\title{
Intervention vignettes as a qualitative tool to refine complex intervention design
}

\author{
Pat Hoddinott ${ }^{1 *}$, Heather Morgan², Gill Thomson ${ }^{3}$, Nicola Crossland ${ }^{3}$, Leone Craig ${ }^{2}$, Jane Britten ${ }^{1}$, Shelley Farrar ${ }^{2}$, \\ Rumana Newlands ${ }^{2}$, Kirsty Kiezebrink ${ }^{2}$, Joanne Coyle ${ }^{2}$
}

From 2nd Clinical Trials Methodology Conference: Methodology Matters

Edinburgh, UK. 18-19 November 2013

\section{Background}

In trial design, decisions are made about which intervention components/processes to standardise and which remain flexible to maximise utility and/or effectiveness. The intervention-context-system fit for complex interventions impacts on trial recruitment, delivery and outcomes. Survey vignettes and discrete choice experiments are quantitative researcher led approaches which focus on a few measurable attributes. Our aim was to explore the utility of qualitative vignettes as a methodological tool allowing service users/providers to contribute to intervention design.

\section{Methods}

A case series of four acceptability and feasibility studies (qualitative interviews and focus groups) with service users and providers. Data were collected at different pre-trial stages: i) vignettes of studies in a systematic review of incentives for breastfeeding and smoking cessation in pregnancy, subsequently modified following emergent qualitative analysis; ii) emergent vignettes in the last of up to 8 serial qualitative interviews investigating infant feeding behaviour, following a systematic review showing poor generalizability of effective interventions in the UK context; iii) intervention vignettes of an effective intervention (groups for weight management) to refine the design for a new population (women treated for breast cancer) and iv) emergent intervention vignettes explored at a second interview with obese older adults.

\section{Findings}

Illustrations of how qualitative vignettes can complement quantitative design tools will be presented.

${ }^{1}$ University of Stirling, Stirling, UK

Full list of author information is available at the end of the article

\section{Conclusion}

Carefully constructed qualitative vignettes combining known effective and emergent promising intervention aspects can optimise trial design. When talking service users and providers through a potential intervention, different perspectives emerge compared with responses to closed or more abstract questions.

\section{Authors' details \\ 'University of Stirling, Stirling, UK. ${ }^{2}$ University of Aberdeen, Aberdeen, UK. ${ }^{3}$ University of Central Lancashire, Preston, UK.}

Published: 29 November 2013

doi:10.1186/1745-6215-14-S1-055

Cite this article as: Hoddinott et al: Intervention vignettes as a qualitative tool to refine complex intervention design. Trials 2013 14(Suppl 1):055.

Submit your next manuscript to BioMed Central and take full advantage of:

- Convenient online submission

- Thorough peer review

- No space constraints or color figure charges

- Immediate publication on acceptance

- Inclusion in PubMed, CAS, Scopus and Google Scholar

- Research which is freely available for redistribution 